\title{
«ПРЕДУПРЕДИТЕЛЬНОЕ ПРАВОСУДИЕ» В УСЛОВИЯХ ЦИФРОВИЗАЦИИ: РОССИЙСКИЙ И ЗАРУБЕЖНЫЙ ОПЫТ
}

\author{
(C) 2020 Скачкова О.С. \\ кандидат юридических наук \\ Самарский государственный экономический университет, Россия, Самара \\ E-mail:Yarmoluik@mail.ru
}

В представленной статье рассматриваются вопросы информатизации нотариальных процедур, которые обусловлены развитием российской цифровой экономики. Приводится обоснование участия нотариального элемента в электронном гражданском обороте, как необходимости придания действиям и сделкам участников экономических отношений аутентичности. В связи с этим исследуются электронные инструменты нотариальной деятельности, предпринимается попытка исследования электронизации нотариальных и иных юридических процедур с позиции принципа личного участия. В настоящей работе выявляются как преимущества. так и недостатки информатизации нотариальных систем как России, так и некоторых иностранных государств мирового сообщества. Авторы приходят к выводу о том, что существующая тенденция информатизации различных сфер государственной деятельности, экономической и гражданской жизни общества, безусловно, должна развиваться, но с учетом сведения к минимуму ее недостатков.

Ключевые слова: Электронный нотариат, информатизация нотариального процесса, идентификация личности, цифровая экономика

Развитие цифровой экономики в России приоритетное направление государственной политики. До 2018 г. регулирование в данной сфере осуществлялось в рамках Программы Правительства РФ «Цифровая экономика, в настоящее время в Программе Правительства «Цифровая экономика 2024 г. определены перспективы развития цифровизации экономики. Государство уделяет значительное внимание развитию информационно-коммуникативных технологий в экономике, государственном управлении. Информатизация многих сфер общественной жизни обусловила появление «электронного правительства», «электронного правосудия», «цифровых сделок», «электронного нотариата». Исторически одним их правовых институтов обеспечивающим достоверность гражданских прав и обязанностей является институт нотариального удостоверения актов. Роль информационных технологий нотариальной деятельности как необходимого элемента цифровой экономики активно обсуждается в последнее время на самом высоком уровне. Так, дискуссионные вопросы развития правового регулирования информационных технологий нотариальной деятельности становятся предметом регулярных обсуждений нотариальным сообществом и государственной властью [1].
Становится очевидным, что современный новый формат экономических отношений требует аналогичного формата гарантий стабильности гражданского оборота. Нотариальное придание аутентичности актам одно их необходимых условий защиты гражданских прав физических и юридических лиц, предупреждения возникновения спорных ситуаций в коммерческой практике.

Многими зарубежными авторами исследуется значимость института нотариата в как экономических отношениях, так и в сохранении правовой безопасности и культурного наследия [См., например: 2]; в обеспечении правовой легальности процедур принятия решений в компаниях Хортватии [3].

Несмотря на значимость электронной составляющей нотариата и широко применяемого термина «электронный нотариат», следует отметить, что нормативного закрепления содержания понятия «электронный нотариат» отсутствует. И поэтому под данным термином в настоящее время понимается совокупность всех «информационных технологий» начиная с включения в данное понятие электронных реестров, электронной подписи нотариусов, заканчивая электронным документооборотом и совершением нотариальных действий в элек- 
тронной форме. Представляется, что суть «электронного нотариата» заключается в совершении нотариальных действий в электронной форме и в организации электронного нотариального документооборота. Здесь можно провести аналогию с электронным правосудием «цифровым судопроизводством», организованном в Китае: онлайн-суд Hangzhou Internet Court принимает к рассмотрению иски о нарушении интеллектуальных прав в интернете, а судебное производство полностью осуществляется в режиме реального времени на веб-странице суда.

И, если говорить о электронном правительстве и цифровой экономике. то электронная коммерческая деятельность развивается не только внутри стран, а на уровне международных отношений. Здесь примечателен опыт Эстонии так, C. Sullivan, E. Burger отмечают, что Эстония в декабре 2014 года стала первой страной которая открыла свои цифровые границы, чтобы любой человек любой точке мира мог подать заявку на получение статуса электронного резидента. Что предоставляет возможность резидентам при помощи ID вступать в коммерческие отношения с частными и государственными компаниями [4].

Следует рассмотреть конкретные элементы электронного нотариата, которые снижают временные и экономические затраты, могут повлиять на эффективность коммерческой деятельности и обеспечить правовую безопасность субъектов экономических отношений:

1. В корпоративных отношениях немаловажным являются действия нотариуса, направленные на защиту прав собственников бизнеса. Например, как в России, так и в мировой практике закреплено удостоверение протоколов собраний участников организации. В Германии, Австрии, все действия, которые касаются структурных изменений компаний требуют обязательного удостоверения нотариусом, это обеспечивает стабильность, безопасность экономической ситуации в стране, что в свою очередь повышает инвестиционную привлекательность. В России с 2009 г. также введена обязательная нотариальная форма сделок с долями в уставном капитале, которая обеспечила защиту прав собственников бизнеса в рейдерских захватах. развитие цифрового обмена между нотариусами и госрегистраторами сделало востребованной услугу по электронной регистрации юридического лица через нотариуса (в 2017 г. воспользовались более 140000 предпринимателей). в практике правового регулирования данной процедуры зарубежных стран отмечается, что возможно введение онлайн-регистрации компаний в качестве обязательной, государства должны устанавливать как электронные средства идентификации, так и участие нотариуса, обеспечивающего достоверность личного участия заявителя в подписании электронной подписью заявлений.

2. Организация функционирования единой информационной нотариальной системы (ЕИНС) позволила наконец то решить проблему с определением действительности доверенностей на действия, подлежащих госрегистрации. ЕИНС России содержит электронные реестры, среди которых в коммерческой практике наиболее востребованы реестр доверенностей (предприниматели и граждане обращались 1,6 млн. раз.) и реестр уведомлений о залоге движимого имущества.

3. Перевод документов бумажной формы в электронную и наоборот, просто необходим в современном ритме жизни для частого и дистанционного предъявления документов при совершении юридически значимых действий, сделок. В 2018 году бизнес и граждане воспользовались ею на 50 процентов чаще - более одного миллиона раз. Всё чаще к нотариусу приходят для того, чтобы сразу создать документ в электронном виде, чтобы удобно и быстро оперировать им в любом количестве копий файла.

4. Полезным электронным инструментом нотариата может стать принятие в депозит нотариуса денежных средств. ценных бумаг по исполнению денежных договорных обязательств. В перспективе данное действие российский законодатель считает возможным совершать в электронной форме.

5. Дистанционное нотариальное удостоверение сделок с недвижимостью. Мы подошли наверное к главному востребованному электронному механизму российского нотариата, обусловленному потребностями развивающихся цифровых коммерческих отношений[5].

По мимо удостоверения сделок с недвижимостью в электронной форме, указанным проектом в качестве перспективы устанавливается перечень нотариальных действий, которые могут быть совершены удаленно в электронной форме, без личной явки обратившегося лица к нотариусу, и порядок их совершения: свидетельствование верности перевода документов с одного языка на другой, передача докумен- 
тов, взыскание денежных сумм или истребование имущества от должника по исполнительной надписи нотариуса.

6. Создание электронных медицинских карт может оказаться эффективным способом передачи данных организации работниками, в случаях обязательного периодичного медицинского осмотра. Так, в некоторых странах, разработаны механизмы аутентификации и авторизации при участии нотариуса для электронного управления медицинскими записями [6].

Одной из перспективных мер правового регулирования, устраняющей препятствия в развитии коммерческих международных отношений является унификация форматов электронного документооборота не только внутри страны между госорганами, а унификация в международном масштабе. Так, в рамках создания единого электронного пространства доверия на территории государств-членов ЕАЭС, институт электронного нотариата должен обеспечить обмен электронными нотариальными актами.

Положительные стороны в цифровизации нотариата безусловно, очевидны и отвечают, соответствуют общественным потребностям в современных информационных условиях. Но все же вызывают некоторые опасения. Которые связаны в первую очередь с соотношением «электронной идентификации» с правами личности. Думается, что правовое регулирование должно ограничить обязательность включения в электронные системы, обязательность идентификации личности строго ограниченным кругом случаев, в целом предоставив человеку идентифицироваться или нет по своему свободному личному усмотрению. Еще одним аспектом, требующим внимания является - ограничение права на личное участие. Право на личное участие в разбирательстве дела подвергается трансформации в судебных процессах в результате применения электронных технологий [7].

Здесь следует отметить положительную практику Китая- рассмотрение дел в Интернет-суде происходит только при условии подтверждения личности сторон единой платформы идентификации. технологии распознавания лиц и аутентификации реальных имен. Также принцип личного участия видоизменяется и в нотариальной деятельности. Стало возможным совершение некоторых нотариальных действий в электронной форме, принадлежность подпи- си лицу в современное время удостоверяется путем проверки электронной подписи. Но, все же данный принцип (личного участия) осуществления нотариального процесса не должен нивелироваться в таких действиях, где нотариусу необходимо выяснение волеизъявления стороны и проверки дееспособности лица. Вопросы проверки дееспособности, идентификации личности при использовании цифровых подписей в случаях возможных мошенничеств, использования без ведома человека или путем введения в заблуждение, подделки электронной подписи требует особого внимания. Перспективой развития является предоставление доступа к биометрическим данным, что будет помогать устанавливать личность, и доступа к информации о судебных решениях об ограничении дееспособности лица. Проблему применения цифровой подписи и идентификации личности предлагается решить при использовании посредством мобильного идентификатора [8].

Проблемой не только российского нотариата, но и зарубежных систем является организация хранения информации, обеспечение безопасности нотариального архива. В США, например, наблюдается возврат к хранению важной документации в бумажном виде. На разработку информационных технологий безопасности российское государство выделяет немалые средства, на реализацию проекта «Информационная безопасность» программы «Цифровая экономика» задачей которого является создание безопасной и устойчивой информационной инфраструктуры для граждан и представителей бизнеса, государства в цифровом пространстве. Хотелось бы, чтобы в реализацию данного проекта входило решение проблемы с организацией нотариальных архивов, так как нотариусы осуществляют публичные функции удостоверения документов от имени государства и хранение таких документов, думается, требует участия государства. Пока федеральная нотариальная палата содержит эти архивы за свой счет. Нотариальному сообществу России еще предстоит организовать и выполнить существенную работу по переводу архивных документов в электронный вид. Одним из решений длительного хранения электронных документов предлагается использование микрофильминга [9]. Нотариусы Германии уже ведут активную работу по разработке к 2020 г. центрального электронного архива, который оснащен четырехуровневой системой защиты. А 
во Франции такой архив должен функционировать с 2021 г.

Один из насущных вопросов, требующих совместного исследования нотариального сообщества и специалистов IT-индустрии - использование технологии распределенного реестра (Блокчейн) в нотариальной деятельности. Эта проблема обусловлена разработкой сервисов, мобильных приложений, которые позволяют идентификацию, автоматизацию видеоинтервью (сервис Interview); хранить, добавлять, просматривать и распечатывать документы, записи которых зашифрованы криптографически и защищены блокчейном от редактирования или удаления (сервисы компании BLOCKNOTARY Timestamp, Journal); производить «нотаризацию», т.е. фиксацию и запись телефонных звонков для сохранения в неизменном виде с подтверждением даты и времени (SilentNotaru); Мы уже можем наблюдать практику использования таких сервисов в деятельности нотариусов, например, цифровое нотариальное удостоверение в Италии на основе блокчейна позиционируется как перспективная услуга, разрабатываются цифровые нотариальные решения с дополнительной безопасностью [10]. На Национальном конгрессе итальянских нотариусов в октябре 2017 г. объявлено о создании сети нотариусов Notarchain, которая запущена в практическую деятельность в конце 2018 г., безусловно, инте- ресна эта пусть совсем недолгая нотариальная практика итальянских коллег.

Но такая автоматизация блокчейнов, учитывая тенденцию их признания в качестве цифровых доказательств (в сентябре 2018 г. Верховный народный суд КНР обязал интернет-суды рассматривать цифровые блокчейн-записи в качестве доказательств при рассмотрении дел, связанных с использованием интернета; в 217 г. в США, штаты Аризана, Делавэр признают блокчейн в качестве юридического доказательства), может вытеснить человеческий фактор в лице нотариуса из процедуры удостоверения подлинности документа, действия. Преимущества и сложности использования блокчейна в электронных нотариальных процедурах-предмет интереса мирового сообщества. Так, O. Lasmoles, отмечает, что блокчейны способствовали развитию смарт- контрактов, но породили множество вопросов о добросовестности обязательств, защите личных данных [11]. Опыт Эстонии в этом вопросе положителен: оказание услуг нотариуса в рамках деятельности е- Residency Эстонии осуществляется на основе блокчейн, что меняет способ аутентификации идентификационной информации[4]. Китайские ученые IоT предлагают новые усовершенствования консорциума блокчейн в построении межсетевой модели электронного доступа, но с использованием подтверждения через нотариальный механизм[12].

\section{Библиографический список}

1. Нотариат необходим «цифровой экономике»: обсуждение в общественной палате РФ от 20.09.2019 [Электронный ресурс]. URL: https://notariat.ru/ru-ru/news/notariat-neobhodim-cifrovoj-ekonomike-obsuzhdenie-vobshestvennoj-palate-rf. (Дата обращения: 01.03.2020)

2. Павич Д., Гагро П., Балатинак К. (2019). Система управления государственной нотариальной службой. Материалы конференции «Междисциплинарные исследования в области управления» (IMR). Опатия, ХОРВАТИЯ. 2019. С. 275-294. . [Электронный ресурс] // URL: www. webofknowledge.com (дата обращения: 11.03.2020).; Pavic, D., Gagro, P ., Balatinac, K. (2019). Management system of the notary public service. Paper presented at the Proceeding: Interdisciplinary Management Research XV (IMR) Conference. Opatija. CROATIA 2019. $275-294$. Retrieved from: www. webofknowledge.com (дата обращения: 11.03.2020).

3. Гарго П., Люстина Д., Баран А. Управление данными в государственной нотариальной службе. Материалы XIV (IMR) конференции «Междисциплинарные исследования в области управления», Опатия, Хорватия. 2018. C.1069-1095. [Электронный ресурс] // URL: www. webofknowledge.com. (дата обращения: 11.03.2020).; Gargo, P. Ljustina, D. Baran, A. (2018) Data management and knowledge management in notary public service. Paper presented at the Proceeding: Interdisciplinary Management Research XIV (IMR) Conference, Opatija, CROATIA 2018, 1069-1095. Retrieved from www. webofknowledge.com.

4. Sullivan C., Burger E. Электронная резиденция и блокчейн. // «Компьютерный закон и безопасность» № 33 (4), C. 470-481. doi: 10.1016 / j.clsr.2017.03.016 [Электронный ресурс] // URL: www.scopus.com (дата обращения: 11.03.2020).; Sullivan, C., \& Burger, E. E-residency and blockchain. Computer Law and Security Review, 33(4), 470-481. doi:10.1016/j.clsr.2017.03.016 Retrieved from www.scopus.com 
5. Проект Федерального закона N 750699-7 «О внесении изменений в Основы законодательства Российской Федерации о нотариате» ред., внесенная в ГД ФС РФ [Электронный ресурс] // URL: http://www.consultant.ru/ law/hotdocs/58439.htm, (дата обращения: 07.03.2020).

6. Lo N.-W., Wu C.-Y, Chuang Y.-H. Аутентификация и авторизация для долгосрочного электронного управления здравоохранением. Материалы 8-й Международной конференции по достижениям в области информационных технологий, Макао. PEOPLES R CHINA, 2016. C.145-153. [Электронный ресурc] // URL: www. webofknowledge.com (дата обращения: 11.03.2020).; Lo, N.-W., Wu, C.-Y, Chuang, Y.-H. (2018). An authentication and authorization for long-term electronic health management. Paper presented at the Proceeding: 8TH INTERNATIONAL CONFERENCE ON ADVANCES IN INFORMATION TECHNOLOGY, Macau, PEOPLES R CHINA 2016, 145-153.: Retrieved from: www. webofknowledge.com (дата обращения: 11.03.2020).

7. Павлушина А.А., Скачкова О.С.Институт участия в разбирательстве дела в условиях информатизации судебного процесса. Материалы Всероссийской научно-практической конференции: «Защита прав: проблемы теории и практика реализации». Верховный суд РФ; Северо-Западный филиал «Российский государственный университет правосудия». Ст- Петербург. 2014. С.117-123.

8. Э. Хусни (2017). Цифровая подпись с использованием национальной идентификации в качестве мобильного идентификатора. Материалы Международного семинара по интеллектуальным технологиям и их применению «Последние тенденции в интеллектуальных вычислительных технологиях для устойчивой энергетики», ISITIA. 2016. С. 261-264. doi: 10.1109 / ISITIA.2016.7828668 [Электронный ресурс] // URL: www.scopus. com (дата обращения: 15.03.2020).; Husni, E. (2017). Digital signing using national identity as a mobile ID. Paper presented at the Proceeding - 2016 International Seminar on Intelligent Technology and its Application, ISITIA 2016: Recent Trends in Intelligent Computational Technologies for Sustainable Energy, 261-264. doi:10.1109/ ISITIA.2016.7828668 Retrieved from: www.scopus.com

9. Курсер А.Э. Технология микрофильмирования для длительного хранения электронных документов. Вестник архивариуса. 2015. № 1. С. 241-250. [Электронный ресурс] // URL: www. webofknowledge.com(дата обращения: 07.03.2020).; Kurcer A.E. Microfilming technology for long-term storage of electronic documents. Herld of an archivist. 2015. 1. 241-250.

10. Менегетти А., КвинтаваллеА.О., Сала М. и Томази А.Двойное нотариальное заверение с дополнительной безопасностью. Материалы семинара CEUR, 2019, № 2334. C.32-42. [Электронный ресурc] // URL: www. scopus.com (дата обращения: 07.03.2020).; Meneghetti, A., Quintavalle, A. O., Sala, M., \& Tomasi, A. (2019). Twotier blockchain timestamped notarization with incremental security. Paper presented at the CEUR Workshop Proceedings, 2334 32-42. Retrieved from www.scopus.com (дата обращения: 07.03.2020).

11. Lasmoles O.Итог: Трудности, с которыми сталкивается правовая система в примирении с блокчейнами. [LA DIFFICILE APPRÉHENSION DES BLOCKCHAINS PAR LE DROIT], 2018. [Электронный ресурc] //// URL: www. scopus.com (дата обращения: 07.03.2020).; Lasmoles, O. (2018). Summary: Difficulties faced by the legal system in coming to terms with blockchains. [LA DIFFICILE APPRÉHENSION DES BLOCKCHAINS PAR LE DROIT] Revue Internationale De Droit Economique, 32(4), 453-469. doi:10.3917/ride.324.0453 Retrieved from www.scopus.com

12. Jiang Y., Wang C., Huang Y., Long S., Hио Y. «Кросс-цепное решение для интеграции ІоТ-клубка для управления доступом к данным» // Материалы IEEE 2018 Международного конгресса по киберматике: конференции IEEE 2018. Cybermatics, 2018. [Электронный ресурc] // URL: www.scopus.com (дата обращения: 15.03.2020).; Jiang, Y., Wang, C., Huang, Y., Long, S., \& Huo, Y. (2018). A cross-chain solution to integration of IoT tangle for data access management. Paper presented at the Proceedings - IEEE 2018 International Congress on Cybermatics: 2018 IEEE Conferences on Internet of Things, Green Computing and Communications, Cyber, Physical and Social Computing, Smart Data, Blockchain, Computer and Information Technology, iThings/GreenCom/CPSCom/ SmartData/Blockchain/CIT2018, 1035-1041. doi:10.1109/Cybermatics_2018.2018.00192 Retrieved from www. scopus.com 